Başvuru : 09.05.2016

Kabul : :26.12.2016

\title{
Küresel Krizi İzleyen Dönemde Para Politikası ve Varlık Fiyatları: Türkiye Örneği
}

\begin{abstract}
Küresel Krizi İzleyen Dönemde Para Politikası ve Varlık Fiyatları: Türkiye Örneği

Öz

Bu çalışmanın amacı, küresel krizi izleyen dönemde Türkiye Cumhuriyet Merkez Bankası'nın (TCMB) varlık fiyatlarındaki değişimlere tepki verip vermediğini incelemektir. Bu amaç doğrultusunda, çalışmada TCMB için oluşturulan tepki fonksiyonu döviz kuru açığı ve borsa endeksi açığıyla genişletilmiştir. Ampirik analizin sonuçlarına göre, TCMB faiz ayarlamaları yaparken enflasyon beklentisi ile enflasyon hedefi arasındaki fark ve döviz kuru açığıyla ilgilenmektedir. Bu sonuçlar, küresel krizi izleyen dönemde döviz kurunun enflasyon beklentilerini etkilemenin ötesinde TCMB'nin faiz ayarlamaları üzerinde anlamlı etkilere sahip olduğunu göstermektedir.
\end{abstract}

Anahtar Kelimeler: Türkiye Cumhuriyet Merkez Bankası, Tepki Fonksiyonu, Varlık Fiyatları, ARDL Yöntemi
Monetary Policy and Asset Prices in the Period Following the Global Crisis: The Case of Turkey

\section{Abstract}

This paper aims at examining whether the Central Bank of the Republic of Turkey (CBRT) reacts to changes in asset prices in the period following the global crisis. To this end, the reaction function of the CBRT is extended with exchange rate gap and stock market index gap. According to the findings of the empirical analysis, the CBRT considers the difference between expected inflation and inflation target and exchange rate gap while it is adjusting interest rates. These findings show that exchange rates have significant effects on the interest rate adjustments of the CBRT beyond affecting inflation expectations in the period following the global crisis.

Keywords: The Central Bank of the Republic of Turkey, Reaction Function, Asset Prices, ARDL Method.

\section{Giriş}

Günümüzde pek çok merkez bankası kısa vadeli/gecelik faiz oranlarını kontrol etmeyi ve böylece enflasyona ve çıktıya istikrar kazandırmayı amaçlamaktadır. Söz konusu merkez bankaları kısa vadeli faiz oranlarını kontrol ederek uzun vadeli kredi, mevduat ve devlet tahvili faiz oranlarını etkilemeye çalışmaktadır. Bu çerçevede, bir merkez bankasının tepki fonksiyonu, merkez bankasının ekonomideki gelişmeler karşısında kısa vadeli faiz oranlarını nasıl ayarladığını göstermektedir (Judd ve Rudebusch, 1998; Bulut, 2016). Amerikan Merkez Bankası'nın (FED) enflasyondaki ve çıktı açığındaki değişimler karşısında kısa vadeli faiz oranlarını nasıl ayarladığını göstermeye çalışan Taylor (1993)'ın öncü çalışmasından beri merkez bankalarının tepki fonksiyonları üzerine birçok çalışma yapılmıştır (Clarida ve Gertler, 1997; Judd ve Rudebusch, 1998; Clarida vd., 1998, 1999, 2000; Sutherland, 2010; Kumar, 2013). Taylor (1993)'ın FED'in faiz ayarlamalarını göstermeye çalışırken ortaya koyduğu denklem Taylor Kuralı olarak bilinmektedir. Taylor Kuralı, değişkenlerin cari değerlerini kullanıp para politikasının ekonomi üzerindeki gecikmeli etkisini dikkate almadığı için Clarida vd. (1998), para politikasının enflasyonu gecikmeyle etkilediğini dikkate alan bir tepki fonksiyonu geliştirmişlerdir. Clarida vd. (2000)'nin ortaya koydukları tepki fonksiyonu ise, para politikasının hem enflasyon hem de çıktı üzerindeki gecikmeli etkilerini dikkate almaktadır.

Eichengreen vd. (2011: 1)'nin belirttikleri üzere, 1990'ların başından beri artan sayıda merkez bankası esnek enflasyon hedeflemesi rejiminde uzlaşmış ve bu rejim bir süre için makroekonomik istikrarı ulusal ve uluslararası seviyede sağlamayı başarmıştır. Yazarlara göre, açıkça

\footnotetext{
${ }^{1}$ Arş. Gör. Dr., Ahi Evran Üniversitesi IiBBF, iktisat Bölümü. ubulut@ahievran.edu.tr
} 
ilan etmeseler de, bu dönemde FED ve Avrupa Merkez Bankası'nın para politikası stratejileri esnek enflasyon hedeflemesine yakındır. 2008 yılında başlayan küresel finansal krizden önce tepki fonksiyonlarına finansal değişkenleri ekleyen bazı çalışmalar (Bernanke ve Gertler, 2000; Cecchetti, 2003; Ramayandi, 2003; Yazgan ve Yılmazkuday, 2007) yapılmış olsa da, küresel krizden önceki baskın görüşe göre, merkez bankaları finansal değişkenlerle sadece bu değişkenler çıktıyı ve enflasyonu etkilediği sürece ilgilenmeli ve finansal istikrarı doğrudan sağlama amacına sahip olmamalıdır (Bernanke ve Gertler, 2001; Eichengreen vd., 2011). Bu görüşe göre, fiyat istikrarını sağlayabilen bir merkez bankası finansal istikrara da katkıda bulunabilecektir (Özatay, 2012: 53). Para politikasının finansal istikrarla doğrudan ilgilenmemesi ve kriz çıktıktan sonra sisteme müdahale etmesi gerektiğini savunan bu baskın görüşün dayanakları şu şekildedir (Eichengreen vd., 2011: 6; Issing, 2011: 5; Agenor ve Silva, 2012: 208-211):

- Varlık fiyatlarındaki balonları tespit etmek zordur. Bu konuda merkez bankaları finansal piyasalardaki diğer aktörlerden daha fazla bilgiye sahip değildir.

- Faiz oranlarının yükseltilmesi varlık fiyatlarında balon oluşmasını engelleyemeyebilir; çünkü piyasa aktörleri bu varlıkları satın almaktan yüksek kazanç bekliyor olabilirler.

- Para politikası balonlarla ilgilenmek için en iyi araç değildir.

- Finansal istikrarı sağlama amacı bulunan bir merkez bankası kredibilite kaybedebilir; çünkü böyle bir amaç toplumun gözünde merkez bankasının fiyat istikrarına yönelik taahhüdünü zayıflatabilir.

2008 krizi, finansal sektörde yaşanan gelişmelerin ekonomik faaliyetler üzerinde tahmin edilenden çok daha fazla etkilerinin olduğunu, finansal krizlerin maliyetlerinin çok yüksek olduğunu ve fiyat istikrarının finansal istikrarı daima sağlayamayacağını kanıtlamıştır (Furlanetto, 2011: 91). Bu nedenle, küresel krizden sonra para politikasının finansal piyasalardaki gelişmeleri dikkate alarak yürütülmesini savunan görüşler artmıştır. Bu çerçevede, küresel krizden çıkarılan en önemli derslerden birisi merkez bankalarının fiyat istikrarına odaklanırken finansal sistemde biriken riskleri ve varlık fiyatlarındaki şişkinlikleri göz ardı etmemesi gerektiğidir (Kara, 2012: 10). Bu nedenle, krizden sonra halâ faiz ayarlamalarında finansal istikrara dair endişelerin doğrudan dikkate alınmamasını savunan görüşler olsa da (bkz. Svensson, 2010a, 2010b), bazı çalışmalarda tahmin edilen tepki fonksiyonlarında finansal değişkenlere yer verilmiştir (Castro, 2011; Milas ve Naraidoo, 2012; Lange, 2013; Lee ve Son, 2013).

Bu çalışmanın amacı, küresel krizi izleyen dönemde Türkiye Cumhuriyet Merkez Bankası'nın (TCMB) varlık fiyatlarındaki değişime tepki verip vermediğini 2009-2015 dönemine ait verileri kullanarak incelemektir. Bu amaç doğrultusunda, çalışmada TCMB için oluşturulacak tepki fonksiyonu döviz kuru açığı ve borsa endeksi açığıyla genişletilecektir. TCMB'nin tepki fonksiyonuna çeşitli finansal değişkenleri ekleyen önceki çalışmalar dünyada tepki fonksiyonlarında finansal değişkenlerin yer almamasını savunan görüşlerin baskın olduğu dönemde yapılmıştır. Bu çalışmanın kullandığı veri seti ise küresel kriz ortaya çıktıktan sonra başlamaktadır. Bu nedenle, çalışmanın ilgili literatüre temel katkısı, kullandığı veri setinin merkez bankalarının finansal istikrarla doğrudan ilgilenmesini savunan görüşlerin arttığı bir döneme tekabül etmesi olup, çalışma TCMB'nin faiz ayarlamaları konusunda yeni kanıtlar sunmaktadır.

Çalışmanın kalanı şu şekildedir: İkinci bölümde Taylor Kuralı ve ileri bakışlı tepki fonksiyonları sunulmaktadır. Üçüncü bölümde TCMB'nin tepki fonksiyonuna yönelik ampirik literatür verilecektir. Dördüncü bölümde model ve veri seti tanıtılacaktır. Beşinci bölüm, ampirik analizde 
kullanılacak metodolojinin verilmesine ayrılmıştır. Altıncı bölümde tahmin sonuçlarına yer verilecektir. Çalışmanın son bölümü olan sonuç bölümünde ise analiz sonuçları özet olarak sunulacaktır.

\section{Taylor Kuralı ve İleri Bakışlı Tepki Fonksiyonları}

Taylor (1993), FED'in faiz oranlarını nasıl ayarlamaya çalıştığını açıklamaya çalışmış ve 19871992 döneminde $A B D^{\prime}$ de gecelik faiz oranlarıyla/federal fon oranlarıyla kendi oluşturduğu eşitlik yardımıyla elde ettiği faiz oranının paralel hareket ettiğini ortaya koymuştur. Taylor (1993)'ın FED'in faiz ayarlamalarını göstermeye çalışırken ortaya koyduğu denklem Taylor Kuralı olarak bilinmektedir.

Taylor Kuralı, kapsamlı bir teorik model ya da yoğun akademik tartışmalar sonucu ortaya çıkmamıştır (Bofinger vd., 2001: 68). Taylor (1993), FED'in federal fon oranlarını sistemli bir biçimde enflasyon oranı ve çıktı açığıyla ilgili sabit bir ilişkiye göre değiştirdiğini savunmuştur (Friedman, 2012: 612). Taylor (1993)'ın elde ettiği ve Taylor Kuralı olarak bilinen denklem şu şekildedir (Taylor, 1993: 202; Judd ve Rudebusch, 1998: 5):

$r=p+0,5 y+0,5(p-2)+2$

Burada;

$r=$ gecelik faiz oranı,

$p=$ enflasyon oranı (içinde bulunulan çeyreğin ve önceki üç çeyreğin enflasyon oranının ortalaması),

2 = fiyat istikrarıyla uyumlu enflasyon oranı ve $A B D^{\prime}$ de denge reel faiz oranı,

y = reel gayri safi yurtiçi hasılanın (GSYH) trendinden/potansiyelinden yüzde sapması.

Reel GSYH'nin potansiyelinden yüzde sapması çıktı açığı olarak adlandırılmakta olup, şu şekilde hesaplanmaktadır:

$y=100\left(Y-Y_{n}\right) / Y_{n}$

$\mathrm{Y}=$ reel GSYH,

$\mathrm{Y}_{\mathrm{n}}=$ reel GSYH'nin trendi.

Taylor (1993), bu eşitliği ekonometrik olarak tahmin etmemiş ve FED'in bu şekilde ağırlık verdiğini varsaymıştır (Judd ve Rudebusch, 1998: 5). Taylor (1993)'ın eşitliğine göre, enflasyon \%2'yi aşarsa ve/veya reel GSYH trendini aşarsa faiz oranları yükselecektir. 1 numaralı denkleme göre enflasyondaki \%1'lik bir artış (azalış) karşısında gecelik nominal faiz oranı \%1,5 artacağından (azalacağından) enflasyondaki artış (azalış) karşısında gecelik reel faiz oranı yükselecektir (düşecektir).

Taylor Kuralı'na yönelik temel eleştiri, kuralın para politikasının ekonomi üzerindeki gecikmeli etkisini ihmal etmesidir. Clarida vd. (1998), bu eleştiriden hareketle para politikası literatüründe en çok kullanılan tepki fonksiyonunu geliştirmişlerdir. Söz konusu tepki fonksiyonunu elde etmek için yazarlar aşağıdaki eşitlikle başlamaktadırlar:

$i_{t}^{*}=\bar{i}+\beta\left(E\left[\Pi_{t+n} \mid \Omega_{t}\right]-\Pi^{*}\right)+\gamma\left(E\left[y_{t} \mid \Omega_{t}\right]-y_{t}^{*}\right)$

Burada;

$i_{t}^{*}=k ı s a$ vadeli faiz oranının hedef düzeyi,

$\overline{\mathrm{i}}=$ denge nominal kısa vadeli faiz oranı, 
$\Pi_{\mathrm{t}+\mathrm{n}}=\mathrm{t}$ ve $\mathrm{t}+\mathrm{n}$ dönemleri arasındaki enflasyon oranı ( $\mathrm{t}$ döneminde $\mathrm{t}+\mathrm{n}$ dönemi için yapılan enflasyon öngörüsü),

$\mathrm{y}_{\mathrm{t}}=$ reel çıktı düzeyi,

$\Pi^{*}=$ hedeflenen enflasyon oranı,

$y_{t}^{*}=$ potansiyel çıktı düzeyi (ücretler ve fiyatların tam esnek olması durumunda yükselmesi beklenmektedir),

$\mathrm{E}=$ beklenti işlemcisi,

$\Omega=$ merkez bankasının faiz oranlarını ayarladığı dönemde mevcut bilgi.

Clarida vd. (1998), merkez bankalarının faiz oranlarını düzleştirme (smoothing interest rates) eğiliminde olabileceğini belirtmişlerdir. Darıcı (2010: 39)'ya göre, faiz düzleştirme, merkez bankasının kısa vadeli faiz oranını hedef faiz oranına yavaşça uyarlaması olarak tanımlanmaktadır. Bir başka deyişle, kısa vadeli faiz oranının aşama aşama hedefe ayarlanmasıdır (Clarida vd., 1998). Merkez bankalarının faiz oranlarını düzleştirme eğiliminde olabilmesinin nedenleri şu şekildedir (Darıcı, 2010: 55-57):

- Kısa vadeli faizlerin yavaşça uyarlanması finansal kriz intimalini azaltmaktadır; çünkü yavaş uyarlanma sayesinde finansal piyasalardaki hareket ve oynaklık yavaşlayacak ve finansal piyasalarda ani hareketlerin olması önlenecektir.

- Merkez bankaları finansal piyasalardaki faiz oranlarının geniş bir bant içerisinde dalgalanmasını arzu etmemektedir. Faizlerin yavaşça uyarlanması ve daha tahmin edilebilir hale gelmesi, finansal piyasalardaki oynaklığı azaltabilecektir.

- Merkez bankalarının izledikleri faiz politikalarında belirsizliğin azalması, finansal piyasa aktörlerinin kısa vadeli faizler hakkında doğru tahmin yapma şanslarını artırmaktadır.

- Kısa vadeli faizlerdeki kısmi ayarlamalar uzun vadeli faizlerde merkez bankalarının istediği değişikleri yapmasını sağlamaktadır.

- Faizlerin istikrarlı hale gelmesi, bankaların varlık-yükümlülük dengesizliğinden kaynaklanan riskleri azaltmaktadır.

Faiz düzleştirmesini gösteren denklem şu şekildedir:

$i_{t}=(1-p) i_{t}^{*}+p i_{t-1}+v_{t}$

$p$ katsayısı 0 ile 1 arasında olup, faiz düzleştirmesinin derecesini gösterirken, $v_{t}$ faiz oranına rassal dışsal bir şoku temsil etmektedir.

3 numaralı denklem için $\alpha \equiv \overline{\mathrm{i}}-\beta \Pi^{*}$ ve $\mathrm{x}_{\mathrm{t}} \equiv \mathrm{y}_{\mathrm{t}}-\mathrm{y}_{\mathrm{t}}^{*}$ olarak tanımlandığında, 5 numaralı denklem elde edilecektir:

$i_{t}^{*}=\alpha+\beta E\left[\Pi_{t+n} \mid \Omega_{t}\right]+\gamma E\left[x_{t} \mid \Omega_{t}\right]$

4 numaralı ve 5 numaralı denklemler birleştirildiğinde aşağıdaki denklem elde edilmektedir:

$\mathrm{i}_{\mathrm{t}}=(1-\mathrm{p})\left\{\alpha+\beta \mathrm{E}\left[\Pi_{\mathrm{t}+\mathrm{n}} \mid \Omega_{\mathrm{t}}\right]+\gamma \mathrm{E}\left[\mathrm{x}_{\mathrm{t}} \mid \Omega_{\mathrm{t}}\right]\right\}+\mathrm{pi}_{\mathrm{t}-1}+\mathrm{v}_{\mathrm{t}}$

Son olarak, gözlemlenemeyen öngörü hataları ifadeden çıkarıldığında tepki fonksiyonu şu şekilde yazılabilmektedir²:

\footnotetext{
${ }^{2}$ Yazgan ve Yılmazkuday (2007), Clarida vd. (1998)'nin tepki fonksiyonunda enflasyon hedefinin yer almamasının gerekçesi olarak gelişmiş ülkelerde enflasyon hedefinin uzun yıllardır sabit olmasını göstermişlerdir. Yazarlara göre, bu durum gelişmekte olan ülkeler için geçerli olmadığından, bu ülkelere yönelik oluşturulacak tepki fonksiyonlarında enflasyon hedefi de yer almalıdır.
} 
$\mathrm{i}_{\mathrm{t}}=(1-\mathrm{p}) \alpha+(1-\mathrm{p}) \beta \Pi_{\mathrm{t}+\mathrm{n}}+(1-\mathrm{p}) \nu \mathrm{x}_{\mathrm{t}}+\mathrm{pi} \mathrm{i}_{\mathrm{t}-1}+\varepsilon_{\mathrm{t}}$

7 numaralı denklemin hata terimi ise şu şekildedir:

$\varepsilon_{\mathrm{t}} \equiv-(1-\mathrm{p})\left\{\beta\left(\Pi_{\mathrm{t}+\mathrm{n}}-\mathrm{E}\left[\Pi_{\mathrm{t}+\mathrm{n}} \mid \Omega_{\mathrm{t}}\right]\right)+\gamma\left(\mathrm{x}_{\mathrm{t}}-\mathrm{E}\left[\mathrm{x}_{\mathrm{t}} \mid \Omega_{\mathrm{t}}\right]\right)\right\}+\mathrm{v}_{\mathrm{t}}$

Hata terimi, enflasyona ve çıktıya ilişkin öngörü hatalarının ve dışsal sapmaların doğrusal bir kombinasyonudur.

Clarida vd. (1998), böylelikle Taylor (1993)'ın geri bakışlı tepki fonksiyonuna karşı ileri bakışlı bir tepki fonksiyonu elde edildiğini vurgulamışlardır. Clarida vd. (1998)'nin oluşturdukları tepki fonksiyonunda en göze çarpan nokta enflasyona ilişkin öngörü rakamları kullanılırken, çıktı açığına ilişkin cari rakamların kullanılmasıdır. Clarida vd. (1998), yaklaşımlarının kısa dönemde fiyat ve ücret katılıklarının olduğu bir yaklaşım olduğunu belirtmişlerdir. Buna göre, nominal faiz oranlarının değiştirilmesiyle yürütülen para politikası, kısa dönemde reel faiz oranı ve reel döviz kurunu etkileyerek çıktıyı etkileyebilmektedir. Clarida vd., iki çalışma daha yayınlayarak bu konuyu aydınlığa kavuşturmaya çalışmışlardır. Clarida vd. (1999), Clarida vd. (1998)'nin savundukları görüşleri tekrarlamışlar ve yaklaşımlarının kısa dönemde fiyat katılıklarının olduğu yeni Keynesyen bir yaklaşım olduğunu ve bu nedenle para politikasının kısa dönemde çıktıyı etkileyebileceğini belirtmişlerdir. Clarida vd. (2000) ise, yeni bir tepki fonksiyonu oluşturmuşlar ve enflasyon için olduğu gibi çıktı açığı için de öngörü rakamlarını kullanmışlardır. Bu tepki fonksiyonu aşağıdaki denklem ile gösterilmektedir:

$\mathrm{i}_{\mathrm{t}}=(1-\mathrm{p}) \alpha+(1-\mathrm{p}) \beta \Pi_{\mathrm{t}+\mathrm{n}}+(1-\mathrm{p}) \gamma \mathrm{x}_{\mathrm{t}+\mathrm{k}}+\mathrm{pi} \mathrm{i}_{\mathrm{t}-1}+\varepsilon_{\mathrm{t}}$

Burada, $x_{t+k} t$ döneminde $t+k$ dönemi için yapılan çıktı açığı öngörüsünü temsil etmektedir.

\section{Literatür Taraması}

TCMB'nin tepki fonksiyonunu tahmin etmeye yönelik ampirik literatür dört grupta sınıflandırılabilir. Birinci gruptaki çalışmalar Taylor Kuralı’nın TCMB için geçerliliğini araştırmakta, ikinci gruptaki çalışmalar TCMB’nin geri bakışlı mı ileri bakışı mı olduğunu belirlemekte, üçüncü grupta yer alan çalışmalar ise TCMB'nin ileri bakışlı bir tutum içinde olduğunu varsayarak tepki fonksiyonu tahmin etmektedir. Dördüncü gruptaki çalışmalar ise, Taylor Kuralı'nı ya da geri ve/veya ileri bakışlı tepki fonksiyonunu finansal değişkenlerle genişletmektedir.

Birinci grupta yer alan çalışma olan Kaytancı (2008), 2002-2007 dönemi verilerini ve vektör otoregresyon (VAR) analizini kullanarak Taylor Kuralı'nın TCMB için geçerli olduğu sonucuna ulaşmıştır. İkinci grupta yer alan çalışmalardan Kesriyeli ve Yalçın (1998), 1987-1998 dönemi verilerini ve iki aşamalı en küçük kareler (EKK) yöntemini kullanarak TCMB'nin geri bakışlı mı ileri bakışlı mı olduğunu tahmin etmişlerdir. Çalışmanın sonucuna göre, TCMB beklenen enflasyon yerine geçmiş enflasyonu dikkate almakta olup, geri bakışlıdır. Adanur-Aklan ve Nargeleçekenler (2008) ise, 2001-2006 dönemi verilerini ve genelleştirilmiş momentler yöntemini (GMM) kullanarak TCMB için hem geri bakışlı hem ileri bakışı tepki fonksiyonu tahmin etmişlerdir. ÇaIışmanın sonuçlarına göre, TCMB hem geçmiş enflasyona hem de gelecekte beklenen enflasyona tepki vermektedir; ancak beklenen enflasyonun katsayısı daha yüksektir. Üçüncü grupta yer alan tek çalışma Bulut (2016)'a aittir. Yazar, 2006-2014 dönemi verilerini ve dinamik EKK yöntemini kullanarak TCMB'nin faiz oranlarını ayarlarken 12 ay ve 24 ay sonrasının enflasyon beklentilerinden hangisini dikkate aldığını araştırmaktadır. Çalışmanın sonuçlarına göre TCMB faiz oranlarını ayarlarken 12 ay sonrasının enflasyon beklentisiyle ilgilenmektedir.

Dördüncü grupta yer alan çalışmalardan Berument ve Malatyalı (2000), 1989-1997 dönemi verilerini ve GMM'yi kullanarak TCMB'nin tepki fonksiyonunu tahmin etmişlerdir. Çalışmanın 
sonuçlarına göre, TCMB enflasyon beklentisi yerine geçmiş enflasyona tepki vermektedir. İlaveten, TCMB döviz kurlarına, kısa vadeli sermaye akımlarına, net yurtiçi ve yurtdışı varlıklara tepki vermemektedir. Berument ve Taşçı (2004), 1990-2000 dönemi verilerini ve GMM'yi kullandıkları çalışmada, TCMB'nin enflasyon beklentisine ve döviz kuruna tepki vermezken, çıktı açığındaki ve uluslararası rezervlerdeki artışlara faiz oranlarını artırarak, enflasyonun cari değerindeki ve geçmiş enflasyondaki artışlara ise beklenenin aksine faiz oranlarını azaltarak tepki verdiği sonucuna ulaşmışlardır. Yapraklı (2007), 2001-2006 dönemine ait verileri ve EKK yöntemini kullanarak gecelik faiz oranlarının enflasyonun, çıktı açığının ve reel efektif döviz kurunun 1 dönem gecikmeli değerinden etkilenip etkilenmediğini incelemiştir. Çalışmanın sonuçlarına göre, gecelik faizler, enflasyon ve çıktı açığı ile pozitif ilişkiliyken, reel efektif döviz kuruyla ilişkisizdir. Yazgan ve Yılmazkuday (2007), 2001-2004 dönemi verilerini ve GMM'yi kullanarak TCMB'nin tepki fonksiyonunu tahmin etmişlerdir. Çalışmadan elde edilen bulgulara göre, TCMB enflasyonda beklenen sapmadaki ve çıktı açığındaki artışa pozitif tepki verirken reel döviz kurundaki değişimlere tepki vermemektedir. Erdem ve Kayhan (2010), geçmişte TCMB'de başkanlık görevinde bulunan Süreyya Serdengeçti ve Durmuş Yılmaz'ın dönemlerini Taylor Kuralı'nın geçerliliği açısından incelenmek istemişler ve enflasyon açığı ve çıktı açığının yanında reel döviz kurunu da kurdukları modele dahil etmişlerdir. Yazarlar, VAR yöntemini kullanarak Serdengeçti dönemi için 2002-2006, Yılmaz dönemi için 2006-2009 dönemine ait verilerden yararlanmıştır. Çalışmanın sonuçlarına göre, Serdengeçti döneminde gecelik faiz oranları çıktı açığıyla negatif, enflasyon açığıyla pozitif ilişkiliyken, reel kurun etkisi çok düşüktür. Yılmaz döneminde ise, gecelik faiz oranları her üç değişkenle de pozitif ilişkilidir. Bu sonuçlardan hareketle yazarlar, TCMB'nin Serdengeçti döneminde Taylor Kuralı'nı izlemezken, Yılmaz döneminde bu kuralı izlediğini belirtmişlerdir. Lebe ve Bayat (2011), 1986-2010 dönemi verilerini ve VAR yöntemini kullanarak ve Taylor Kuralı'nı döviz kurunu kapsayacak şekilde genişleterek kuralın Türkiye'de geçerli olup olmadığını araştırmışlardır. Yazarlar, gecelik faiz oranlarının enflasyondaki sapmayla ilişkisizken, çıktıdaki sapmayla ve döviz kuruyla pozitif ilişkili olduğu sonucuna ulaşmışlar ve bu nedenle Taylor Kuralı'nın Türkiye'de geçerli olmadığını belirtmişlerdir. Taylor Kuralı’nı döviz kurunu içerecek şekilde genişleten ve kuralın Türkiye'de geçerli olup olmadığını inceleyen bir diğer çalışma Gözgör (2012)'e aittir. 2003-2012 dönemi verilerinin ve GMM'nin kullanıldığı çalışmanın sonucuna göre, gecelik faiz oranları enflasyonun hedeften sapmasıyla, çıktı açığıyla ve nominal döviz kuruyla pozitif ilişkilidir. Bu nedenle, çalışmada Taylor Kuralı'nın Türkiye'de geçerli olduğu vurgulanmıştır. Pehlivanoğlu (2014) ise, 1987-2013 dönemi verilerini ve GMM yöntemini kullanarak TCMB için ileri bakışlı bir tepki fonksiyonu tahmin etmiştir. Çalışmanın bulgularına göre, TCMB enflasyonda beklenen sapmadaki ve çıktı açığındaki artışa faiz oranlarını artırarak, kurdaki artışa ise faiz oranlarını azaltarak tepki vermektedir.

Görüldüğü üzere, dördüncü grupta yer alan çalışmalarda ağırlıklı olarak finansal değişken olarak döviz kuru kullanılmış, bazı çalışmalarda TCMB'nin döviz kurundaki değişimlere tepki verdiği sonucuna ulaşıırken, bazı çalışmalarda tepki vermediği sonucuna ulaşılmıştır.

\section{Model ve Veri Seti}

Bu çalışmanın amacı, küresel krizi izleyen dönem için TCMB'nin tepki fonksiyonunu finansal değişkenlerle genişleterek TCMB'nin tepki verdiği değişkenleri tespit etmektir. Çalışmada dünyadaki diğer merkez bankalarının yaptığı gibi TCMB'nin de para politikasının enflasyon üzerindeki etkilerine yönelik gecikmeleri dikkate alarak ve yayınladığı raporlara bağı olarak enflasyon konusunda ileri bakışlı bir tutum içinde olduğu varsayılacaktır. Çıktı açığı konusunda ise, üç al- 
ternatif bulunmaktadır. Birinci alternatif, Clarida vd. (2000)'nin vurguladığı ve özellikle son dönemde yapılan çalışmalarda (Castro, 2011; Lee ve Son, 2013) olduğu gibi para politikasının enflasyonu olduğu gibi çıktıyı da gecikmeli etkilediğini varsayarak çıktı açığı beklentisini kullanmaktır. İkinci alternatif, Clarida vd. (1998)'nin yaptığı ve bu konuda yapılan diğer pek çok çalışmada olduğu gibi (Berument ve Malatyalı, 2000; Faust, Rogers ve Wright, 2001; Berument ve Taşçı, 2004; Yazgan ve Yılmazkuday, 2007; Iklaga, 2008; Shibamoto, 2008), para politikasının çıktı açığı üzerine etkilerine yeni Keynesyen bir perspektiften bakmak ve çıktı açığının cari dönemdeki değerini kullanmaktır. Çıktı açığının cari değerini kullanmak, üstü kapalı bir biçimde, merkez bankasının çok iyi bir öngörü kabiliyetine sahip olduğunu ve cari dönemdeki çıktı açığını tam olarak öngörebildiğini varsaymaktadır. Üçüncü alternatif ise, para politikasının çıktı açığı üzerine etkilerine yine yeni Keynesyen bir perspektiften bakarak çıktı açığının 1 dönem gecikmeli değerini kullanmaktır. TCMB'nin çıktı açığı beklentisine dair dışarıya veri vermemesi, birinci alternatifin kullanılamamasına neden olmuştur. Türkiye'de GSYH verilerinin 2,5-3 ay içinde açıklanması TCMB'nin de diğer iktisadi aktörler gibi cari dönemdeki çıktı açığı verisini bilememesine neden olmaktadır. Bu noktada TCMB'nin cari dönemdeki çıktı açığını tam olarak öngöremediğini varsaymanın daha gerçekçi olduğu düşünülmektedir. Bu nedenle, çalışmada çıktı açığının 1 dönem gecikmeli değeri kullanılacaktır. Çıktı açığı hesaplanırken Hodrick ve Prescott (1997) tarafından geliştirilen filtreleme yöntemi kullanılacak olup, çıktı açı̆̆ı Yazgan ve Yılmazkuday (2007)'ın hesapladıkları gibi hesaplanacaktır. Buna göre, $t$ dönemine ait açık rakamını bulmak için filtrelenecek serinin son gözlemi t dönemine aittir. Benzer şekilde, $t+1$ dönemindeki açık rakamını bulmak için ise filtrelenecek serideki son gözlem $t+1$ döneminindir. Bu süreç, örneklemdeki son gözleme kadar devam etmektedir. Bu yöntemin kullanılmasının amacı, ampirik analizi TCMB'nin gözlemleyebildiği açık rakamını dikkate alarak yapmaktır. Dolayısıyla, çalışmada çıktı açığı HP filtresiyle hesaplanacak, çıktı açığına dair 1 dönem gecikmeli değer kullanılacak ve TCMB'nin uyguladığı para politikasının kısa dönemde çıktı üzerine etkide bulunabileceği varsayılacaktır. Çalışmanın birinci bölümünde tartışıldığı gibi, küresel krize kadar olan dönemdeki baskın görüşe göre, merkez bankaları başta varlık fiyatları olmak üzere finansal değişkenlere bu değişkenler enflasyonu ve harcamaları etkilediği sürece tepki vermelidir. Küresel finans krizi ise finansal değişkenlerin seyrinin ekonominin geleceği açısından ne kadar önemli olduğunu göstermiş ve krizden sonra merkez bankalarının tepki fonksiyonlarını tahmin etmeye yönelik bazı çalışmalarda finansal değişkenler enflasyon ve çıktı açığıyla beraber tepki fonksiyonlarına eklenmiştir. Bu çaıışmada enflasyon beklentisi ile çıktı açığının yanı sıra, modele eklenecek diğer değişkenler döviz kuru açığı ve borsa endeksi açığıdır. Bu değişkenler HP filtresiyle çıktı açığının hesaplandığı gibi hesaplanacaktır. Dolayısıyla, TCMB'nin tepki fonksiyonuna eklenecek ve enflasyon bekleyişlerini etkilemenin ötesinde TCMB'nin faiz ayarlamalarına etki edip etmediği incelenecek finansal değişkenler döviz kuru açığı ve borsa endeksi açı̆̆ıdır. ${ }^{3}$

\footnotetext{
${ }^{3}$ TCMB'nin finansal değişkenlere ait cari değerler yerine neden uzun vadeli trendden sapmayı ifade eden değerlere tepki vermesinin beklendiği çıktı açığından hareketle açıklanabilir. Nasıl ki TCMB’nin çıktı yerine çıktının potansiyelinden sapmasını gösteren çıktı açığına tepki vermesi bekleniyorsa, TCMB'nin bu finansal değişkenlerin trendlerinden sapmalarını ifade eden serilere tepki vermesi beklenmektedir. Çıktı ve finansal değişkenlerdeki aşağı ya da yukarı yönlü her harekete tepki vermesi mantıksız olan TCMB için önemli olan çıktı ve finansal değişkenlerin çok hızı biçimde artması ve azalması anlamına gelebilen uzun vadeli trendlerden pozitif ve negatif sapmalarıdır. İlaveten, ilgili finansal değişkenlerin gelişimlerine ilişkin senaryolar oluşturularak bu konu daha da berraklaştırılabilir. Örnek olarak, döviz kurunun kısa sürede çok düştüğü ve dolayısıyla TL’nin yabancı paralar karşısında ciddi anlamda değer kazandığı bir ortamda, döviz kurunda gözlenecek olası yukarı yönlü bir hareket karşısında TCMB'nin faiz oranlarını artırarak tepki vermesini gerektirecek bir durum yoktur. Çünkü, muhtemelen TL halâ aşırı değerli olacak ve makroekonomik dengeler açısından TL'nin
} 
Bu açıklamaların ardından, çalışmada tahmin edilecek model şu şekilde oluşturulmaktadır:

$\mathrm{i}_{\mathrm{t}}=\beta_{0}+\beta_{1}\left(\Pi_{\mathrm{t}+\mathrm{m}}^{\mathrm{e}}-\Pi_{\mathrm{t}+\mathrm{m}}^{\mathrm{t}}\right)+\beta_{2} \mathrm{y}_{\mathrm{t}-\mathrm{n}}^{\mathrm{gap}}+\beta_{3} \mathrm{exc}_{\mathrm{t}}^{\text {gap }}+\beta_{4} \mathrm{sm}_{\mathrm{t}}^{\text {gap }}+\varepsilon_{\mathrm{t}}$

Burada;

$\mathrm{i}_{\mathrm{t}}=\mathrm{t}$ dönemi için gecelik faiz oranı,

$\pi_{\mathrm{t}+\mathrm{m}}^{\mathrm{e}}=\mathrm{m}$ dönem sonrasının yıllık enflasyon beklentisi,

$\pi_{\mathrm{t}+\mathrm{m}}^{\mathrm{h}}=\mathrm{m}$ dönem sonrasının yıllık enflasyon hedefi,

$\mathrm{y}_{\mathrm{t}-\mathrm{m}}^{\mathrm{gap}}=\mathrm{t}-\mathrm{n}$ döneminin çıktı açığı (\%),

$\operatorname{exc}_{\mathrm{t}}^{\text {gap }}=\mathrm{t}$ dönemi için döviz kuru açı̆̆ı (\%),

$\mathrm{sm}_{\mathrm{t}}^{\text {gap }}=\mathrm{t}$ dönemi için borsa endeksi açığı (\%),

$\varepsilon_{\mathrm{t}}=$ hata terimi.

Çalışmada kullanılacak veriler 2009:1-2015:4 dönemine ait olup çeyrek dönemliktir. TCMB'nin tepki fonksiyonu üzerine yapılan en güncel çalışma olan Bulut (2016)'u izleyerek çaIışmada TCMB'nin 12 ay sonrasının enflasyon beklentisiyle enflasyon hedefi arasındaki farktaki değişime tepki verebileceği düşünülmüş ve $m=4$ olarak belirlenmiştir. Enflasyon beklentileri TCMB'nin beklenti anketinden elde edilmiştir. Her dönem için enflasyon hedefi ise doğrusal interpolasyon yöntemiyle hesaplanmıştır. Çıktı olarak 1998 yılı fiyatları baz alınarak hesaplanan reel GSYH rakamları kullanılmıştır. GSYH rakamları Türkiye' de 2-3 ay içinde açıklandığından, $n=1$ olarak belirlenmiştir. Çalışmada döviz kuru olarak (1 euro+1 dolar)/2 olarak hesaplanan döviz kuru sepeti kullanılmıştır. Borsa endeksi olarak ise 1986=1 olan BIST 100 endeksi kullanılmıştır. Analizde kullanılacak veriler TCMB Elektronik Veri Dağıtım Sisteminden (EVDS) ve Türkiye Bankalar Birliği'nden (TBB) elde edilmiştir.

\section{Metodoloji}

\subsection{Birim Kök Testleri}

Granger ve Newbold (1974), durağan olmayan zaman serileriyle yapılan regresyon analizlerinde sahte regresyon problemiyle karşılaşılabileceğini göstermişlerdir. Buna göre, bu analizlerde hatalı $\mathrm{R}^{2}$, Durbin Watson ve $\mathrm{t}$ istatistikleri yoluyla değişkenler arasında gerçekte bir ilişki olmasa bile mevcut ilişkinin anlamlı olduğu sonuçlarına ulaşılabilecektir (Kennedy, 2006: 349). Bu nedenle, geleneksel ekonometrik yöntemlerle (EKK, 2AEKK, GMM vb.) değişkenler arasında anlamlı ilişkiler elde edilebilmesi için değişkenlere ait serilerin durağan olması gerekmektedir.

Herhangi bir zaman serisinin durağan olup olmadığını araştırmak için korelogram testi ve/veya birim kök testi kullanılmaktadır. Ekonometri literatüründe değişkenlerin durağan olup olmadığını test etmek için Dickey ve Fuller (1981) tarafından geliştirilen Genişletilmiş DickeyFuller (ADF) ve Phillips ve Perron (1988) tarafından geliştirilen PP birim kök testlerinden yaygın olarak yararlanılmaktadır.

tedrici olarak değer kaybetmesi ekonominin yararına olacaktır. Döviz kurunun uzun vadeli trendinden sapması ise, sapmanın yönüne göre TL'nin aşırı değerli ya da aşırı değersiz olması anlamına geldiğinden TCMB bu sapmaya tepki verebilecektir. Döviz kuru için yapılan bu açıklama, borsa endeksi için de yapılabilir. Borsa endeksinin çok hızlı biçimde yükseldiği bir dönemin ardından borsa endeksinde görülecek hafif bir düşme karşısında TCMB'nin faiz oranlarını düşürmesini gerektirecek bir durum yoktur. Bunun nedeni, muhtemelen borsa endeksinin halen uzun vadeli trendinin yukarısında olmasıdır. Bu nedenlerle, çalışmada finansal değişkenlerin cari değerleri yerine bu değişkenlerin uzun vadeli trendlerinden sapmasını ifade eden değerler kullanılacaktır. 
Perron (1989), ADF ve PP birim kök testlerinin seride savaşlardan, doğal afetlerden, ekonomik krizlerden, iktisat politikalarındaki radikal değişimlerden, belirli bir endüstrideki ya da bazı endüstrilerdeki ekonominin tamamını etkileyebilecek çapta gelişmelerden kaynaklanan bir yapısal kırılma olduğunda sıfır hipotezini daha sıklıkla kabul etme eğiliminde olduğunu belirtmiştir. Diğer bir deyişle bu testler, gerçekte durağan bir serinin durağan olmadığına işaret edebilmektedir. Bu nedenle, seriler arasında uzun dönemli ilişkinin varlığı araştırılmadan önce yapısal kırılmayı göz önüne alan birim kök testleriyle de serilerin durağanlıklarının sınanması tavsiye edilmektedir. Bu nedenle, bu çalışmada ADF ve PP birim kök testlerine ilaveten Lee ve Strazicich (2003) tarafından geliştirilen ve serilerde iki yapısal kırılmaya izin veren Lagrange Çarpanı (LM) birim kök testi kullanılacaktır.

İçsel olarak belirlenen iki yapısal kırılmalı LM birim kök testi için öncelikle aşağıdaki denklem tahmin edilmektedir:

$y_{t}=\delta^{\prime} z_{t}+e_{t}, \quad e_{t}=\beta e_{t-1}+\varepsilon_{t}$

Burada, $Z_{t}$ dışsal değişkenler vektörünü ve $\varepsilon_{t} \sim$ iid $N\left(0, \sigma^{2}\right)$ özelliklerine sahip hata terimini ifade etmektedir. Model $A$ düzeyde iki kırılmaya sahip olup, şu şekilde gösterilmektedir: $Z_{t}=[1, t$, $\left.D_{1 t}, D_{2 t}\right]^{\prime}$. Burada, $t \geq T_{B j}+1$ iken $D_{j t}=1$ ve diğer durumlarda 0'dır. $T_{B j}$, kırılma zamanını simgelemektedir. Model $C$ düzeyde ve trendde iki kırılmaya sahip olup, şu şekilde gösterilmektedir: $Z_{t}=\left[1, t, D_{1 t}, D_{2 t}, D T_{1 t}, D T_{2 t}\right]^{\prime}$. Burada, $t \geq T_{B j}+1$ iken $D T_{j t}=t-T_{B j}$ değerini alıp, diğer durumlarda 0 değerini almaktadır. Bu birim kök testi, yapısal kırılmalara hem sıfır hipotezi $(\beta=0)$ altında hem de alternative hipotez $(\beta<1)$ altında izin vermektedir. Model $A^{\prime}$ da (model $C$ için de benzer bir yöntem kullanılabilir), $\beta$ katsayısına bağlı olarak, hipotezler şu şekilde oluşturulmaktadır:

$H_{0}: \quad y_{t}=\mu_{0}+d_{1} B_{1 t}+d_{2} B_{2 t}+y_{t-1}+u_{1 t}$

$H_{1}: \quad y_{t}=\mu_{1}+\nu_{t}+d_{1} D_{1 t}+d_{2} D_{2 t}+u_{2 t}$

Burada, $u_{1 t}$ ve $u_{2 t}$ durağan hata terimlerini göstermektedir. $t=T_{B j}+1$ için $B_{i t}=1$ ve diğer durumlarda 0 olup, $d=\left(d_{1}, d_{2}\right)^{\prime}$ olarak gösterilmektedir. Model $C^{\prime} d e, D_{j t} 12$ numaralı denkleme ve $\mathrm{DT}_{\mathrm{jt}}$ de 13 numaralı denkleme ilave edilmektedir. Sıfır hipotezini gösteren 12 numaralı denklem kukla değişkenleri $\left(B_{j t}\right)$ içermektedir.

iki yapısal kırılmalı LM birim kök test istatistiği şu şekilde elde edilmektedir (Strazicich, Lee ve Day, 2004, s.134):

$\Delta \mathrm{y}_{\mathrm{t}}=\delta^{\prime} \Delta \mathrm{Z}_{\mathrm{t}}+\varphi \tilde{\mathrm{S}}_{\mathrm{t}-1}+\sum \gamma_{\mathrm{i}} \Delta \tilde{\mathrm{S}}_{\mathrm{t}-\mathrm{i}}+\mathrm{u}_{\mathrm{t}}$

Burada, $\tilde{S}_{t}=y_{t}-\widetilde{\Psi}_{x}-Z_{t} \tilde{\delta}$ olup, $t=2, \ldots, T^{\prime}$ dir. $\tilde{\delta}, \Delta y_{t}^{\prime}$ nin $\Delta Z_{t}$ üzerine regres edilmesiyle edilen edilen katsayılar vektörü, $\widetilde{\Psi}_{\mathrm{x}}=\mathrm{y}_{1}-\mathrm{Z}_{1} \tilde{\delta}, \mathrm{y}_{1}$ ve $\mathrm{Z}_{1}$ ise $\mathrm{y}_{\mathrm{t}}$ ve $\mathrm{Z}_{\mathrm{t}}^{\prime}$ nin ilk gözlemleridir. $\Delta$ ve $\mathrm{u}_{\mathrm{t}}$ sırasıyla fark işlemcisini ve hata terimini ifade etmektedir. $\Delta \widetilde{S}_{t-i}, i=1, \ldots, k$ otokorelasyonu düzeltmek için eşitliğe eklenmiştir. $Z_{t}$, veri üretme süreci tarafından tanımlanan dışsal değişkenler vektörünü ifade etmektedir. Sıfır hipotezi $\varphi=0$ olarak gösterilmekte olup, LM test istatistiği $\tilde{\tau}$ şeklinde tanımlanmaktadır.

Kırılma zamanlarını $\left(\lambda_{j}=T_{B j} / T, j=1,2\right)$ içsel olarak belirleyebilmek için minimum LM birim kök testi şu şekilde bir grid aramasından faydalanmaktadır:

$\operatorname{LM}_{\tau}=\inf _{\lambda} \tilde{\tau}(\lambda)$

Kırılma noktalarında test istatistiği minimum değerini almakta olup, Model C için kritik değerler kırılma noktalarına bağlıdır. 
Bu birim kök testlerinin uygulanması sonucunda elde edilen test istatistikleri kritik değerlerden küçük olursa sıfır hipotezler reddedilemeyecek, ilgili serinin durağan olmadığına karar verilecek ve serinin farkı alınarak durağanlık incelemesine devam edilecektir. Durağanlığı sağlamak için d kez fark alınması durumunda, değişkenin d sırasında bütünleşik (entegre) olduğu kabul edilmekte ve değişken I(d) şeklinde gösterilmekteyken, 0 sırasında bütünleşmiş bir değişken ise durağan olmakta ve bu değişken I(0) ile gösterilmektedir.

\subsection{Eşbütünleşme testi}

Durağanlık testleri yoluyla serilerin entegre derecelerinin tespit edilmesinin ardından durağan olmayan serilerle karşılaşılması durumunda seriler arasındaki uzun dönem ilişkilerini belirlemek için eşbütünleşme yöntemleri kullanılmaktadır. Engle ve Granger (1987) tarafından geliştirilen yöntem ve Johansen (1988) ve Johansen ve Juselius (1990) tarafından geliştirilen yöntem, analize dahil edilen tüm serilerin I(1) olmaları durumunda kullanılabilmektedir. Serilerin farklı düzeyde durağan olması durumunda ise, seriler arasındaki eşbütünleşme ilişkisi sınır testi ve ARDL (Autoregressive Distributed Lag) yöntemiyle araştırılmaktadır. Diğer bir ifadeyle, bu yöntem, bağımlı değişken I(1) olmak kaydıyla, bağımsız değişkenlerin I(0) veya I(1) olup olmadıklarına bakmadan seriler arasındaki uzun dönemli ilişkiyi test etme açısından kullanılabilmektedir. Buna göre, ilk olarak Pesaran vd. (2001) tarafından geliştirilen sınır testi yaklaşımı ile seriler arasında uzun dönemli bir ilişkinin olup olmadı̆̆ı tespit edilmektedir. Sınır testi yaklaşımının değişkenler arasında uzun dönemli bir ilişkinin var olduğuna işaret etmesi durumunda da Pesaran ve Shin (1999)'in geliştirdiği ARDL yöntemiyle uzun dönem ve kısa dönem katsayıları hesaplanmaktadır. Pesaran vd. (2001) tarafından kritik değerler türetilirken incelenen değişkenlerin I(0) ya da I(1) oldukları varsayıldığından, ele alınan değişkenler arasında I(2) olan bir değişken olduğunda kritik değerler geçerli olmayacaktır (Abdioğlu ve Terzi, 2009: 203). ARDL yöntemin önemli bir avantajı, küçük örneklemler söz konusu olduğunda da etkin sonuçlar verebilmesidir (Mah, 2000: 240; Narayan ve Narayan, 2004: 102; Öztürk ve Acaravcl, 2011: 2887).

Y'nin bağımlı X'in bağımsız değişkenler olduğu bir modelde seriler arasında uzun dönemli bir ilişkinin var olup olmadığını sınamak için kurulan ve sırasıyla sabitli-trendli, sabitli ve sabitsiztrendsiz olan kısıtsız hata düzeltme modelleri şu şekildedir4:

$$
\begin{aligned}
& \Delta \mathrm{Y}_{\mathrm{t}}=\beta_{0}+\beta_{1} \mathrm{Y}_{\mathrm{t}-1}+\beta_{2} \mathrm{X}_{\mathrm{t}-1}+\beta_{3} \text { trend }+\sum_{\mathrm{i}=1}^{\mathrm{p}} \delta_{\mathrm{i}} \Delta \mathrm{Y}_{\mathrm{t}-\mathrm{i}}+\sum_{\mathrm{i}=0}^{\mathrm{p}} \lambda_{\mathrm{i}} \Delta \mathrm{X}_{\mathrm{t}-\mathrm{i}}+\varepsilon_{\mathrm{t}} \\
& \Delta \mathrm{Y}_{\mathrm{t}}=\beta_{0}+\beta_{1} \mathrm{Y}_{\mathrm{t}-1}+\beta_{2} \mathrm{X}_{\mathrm{t}-1}+\sum_{\mathrm{i}=1}^{\mathrm{p}} \delta_{\mathrm{i}} \Delta \mathrm{Y}_{\mathrm{t}-\mathrm{i}}+\sum_{\mathrm{i}=0}^{\mathrm{p}} \lambda_{\mathrm{i}} \Delta \mathrm{X}_{\mathrm{t}-\mathrm{i}}+\varepsilon_{\mathrm{t}} \\
& \Delta \mathrm{Y}_{\mathrm{t}}=\beta_{1} \mathrm{Y}_{\mathrm{t}-1}+\beta_{2} \mathrm{X}_{\mathrm{t}-1}+\sum_{\mathrm{i}=1}^{\mathrm{p}} \delta_{\mathrm{i}} \Delta \mathrm{Y}_{\mathrm{t}-\mathrm{i}}+\sum_{\mathrm{i}=0}^{\mathrm{p}} \lambda_{\mathrm{i}} \Delta \mathrm{X}_{\mathrm{t}-\mathrm{i}}+\varepsilon_{\mathrm{t}}
\end{aligned}
$$

Sınır testi yaklaşımında $\mathrm{F}$ ve $\mathrm{t}$ istatistikleri kullanılarak seriler arasındaki uzun dönemli ilişki tespit edilebilmektedir. Buna göre, 16 numaralı denklemin sınanması için $F_{I V}$ ve $F_{V}$ istatistiği kullanılmaktadır. $F_{\text {IV }}$ istatistiği, eşitlikteki trend ve değişkenlerin gecikmeli değerlerinin katsayılarının $F$ testi ile bir bütün olarak sıfıra eşit olup olmadıklarını test etmektedir ( $\left.\mathrm{HO}: \beta_{1}=\beta_{2}=\beta_{3}=0\right)$. $F_{V}$ istatistiği eşitlikteki değişkenlerin gecikmeli değerlerinin katsayılarının bir bütün olarak sıfıra eşit olup olmadıklarını test etmektedir $\left(\mathrm{HO}: \beta_{1}=\beta_{2}=0\right)$. TV istatistiği ise, aynı eşitlikteki bağımlı değişkenin gecikmeli değerinin katsayısının sıfıra eşit olup olmadığını test etmektedir (HO: $\beta_{1}=0$ ). Sabitli ve trendsiz modeli gösteren 17 numaralı denklemde $F_{\text {III }}$ istatistiği değişkenlerin gecikmeli değerlerinin katsayılarının bir bütün olarak sıfıra eşit olup olmadığını test ederken

\footnotetext{
${ }^{4}$ Kısıtsız hata düzeltme modelleri kurulurken ve modellerle ilgili açıklamalar yapılırken büyük ölçüde Abdioğlu ve Terzi (2009)'nin çalışmasından faydalanıımıştır.
} 
(HO: $\left.\beta_{1}=\beta_{2}=0\right)$, $t_{\text {III }}$ istatistiği aynı eşitlikte bağımlı değişkenin gecikmeli değerinin katsayısının sıfıra eşit olup olmadığını test etmektedir $\left(\mathrm{HO}: \beta_{1}=0\right)$. 18 numaralı denklem ise, sabitsiz ve trendsiz modeli göstermektedir. Bu eşitlikteki $F_{1}$ istatistiği değişkenlerin gecikmeli değerlerinin katsayılarının bir bütün olarak sıfıra eşit olup olmadığını test ederken ( $\left.\mathrm{HO}: \beta_{1}=\beta_{2}=0\right)$, $t_{\text {। }}$ istatistiği aynı eşitlikteki bağımlı değişkenin gecikmeli değerinin katsayısının anlamlı olup olmadığını sınamaktadır $\left(\mathrm{HO}: \beta_{1}=0\right)$.

Sınır testinde gecikme sayısı belirlenirken AIC (Akaike Bilgi Kriteri) ve SBC (Schwarz Bayesyan Kriteri) gibi kriterler kullanılmaktadır. Burada otokorelasyon probleminin olmadığı gecikme uzunluklarından kriterler için en küçük değeri sağlayan gecikme uzunluğu modellerin gecikme uzunluğu olarak belirlenmektedir. Bu gecikme uzunluğunda hesaplanan test istatistikleri Pesaran vd. (2001) tarafından geliştirilen alt kritik değerlerden küçük olduğu takdirde seriler arasında eşbütünleşme ilişkisinin olmadığını ifade eden sıfır hipotezi kabul edilmekteyken, istatistikler alt ve üst kritik değerler arasında kaldığında uzun dönem ilişkisi hakkında kesin bir yorum yapılamamaktadır. Hesaplanan istatistiklerin üst kritik değerlerden yüksek olması durumunda ise seriler arasında eşbütünleşme ilişkisi olduğu sonucuna varılmaktadır. Seriler arasında eşbütünleşme ilişkisi tespit edildikten sonra uzun ve kısa dönem katsayılarını belirlemek için ARDL modeli kurulmaktadır.

ARDL modelinde uzun dönem katsayısı belirlenirken ilk olarak AIC ve SBC bilgi kriterleri yoluyla gecikme uzunlukları tespit edilmekte ve en uygun $\operatorname{ARDL}(p, q)$ modeli seçilmektedir. Pesaran ve Shin (1999), gecikme uzunluğu belirlenirken AIC yerine SBC'nin baz alınmasının biraz daha iyi sonuçlar vereceğini belirtmişlerdir. Gecikme uzunluğunun belirlenmesinin ardından modelin uzun dönem katsayıları belirlenmektedir. $\operatorname{ARDL}(p, q)$ modeli 19 numaralı denklem ile gösterilmektedir:

$\mathrm{Y}_{\mathrm{t}}=\alpha+\sum_{\mathrm{i}=1}^{\mathrm{p}} \alpha_{\mathrm{i}} \mathrm{Y}_{\mathrm{t}-\mathrm{i}}+\sum_{\mathrm{i}=0}^{\mathrm{q}} \beta_{\mathrm{i}} \mathrm{X}_{\mathrm{t}-\mathrm{i}}+\mathrm{u}_{\mathrm{t}}$

Bu modelden yararlanılarak uzun dönem katsayıları şu şekilde hesaplanmaktadır (Sevüktekin ve Nargeleçekenler, 2010: 500):

$\alpha^{*}=\alpha /\left(1-\sum_{i=1}^{k} \alpha_{i}\right)$

$\beta^{*}=\left(\sum_{i=0}^{k} \beta_{i}\right) /\left(1-\sum_{i=1}^{k} \alpha_{i}\right)$

Hesaplanan bu katsayılar sonucu elde edilen uzun dönem eşbütünleşme modeli ise şu şekildedir:

$\hat{Y}_{t}=\alpha^{*}+\beta^{*} X_{t}$

Uzun dönem katsayıların tahmin edilmesinden sonra değişkenler arasındaki kısa dönem ilişkisi ARDL yaklaşımına dayalı hata düzeltme modeli kurularak elde edilmektedir. Uzun dönem ARDL modelinde olduğu gibi bu modelde de uygun gecikme uzunlukları AIC ve SBC bilgi kriterleri yoluyla belirlenmektedir. Söz konusu model şu şekildedir:

$\Delta \mathrm{Y}_{\mathrm{t}}=\mathrm{Y}_{0}+\mathrm{\gamma}_{1} \mathrm{EC}_{\mathrm{t}-1}+\sum_{\mathrm{i}=1}^{\mathrm{p}} \delta_{\mathrm{i}} \Delta \mathrm{Y}_{\mathrm{t}-\mathrm{i}}+\sum_{\mathrm{i}=0}^{\mathrm{q}} \lambda_{\mathrm{i}} \Delta \mathrm{X}_{\mathrm{t}-\mathrm{i}}+\mathrm{u}_{\mathrm{t}}$

23 numaralı denklemde $\mathrm{EC}_{\mathrm{t}-1}$ olarak ifade edilen hata düzeltme terimi, uzun dönem ilişkisinden elde edilen hata terimi serisinin bir dönem gecikmeli değeri olup, bu değişkenin katsayısı kısa dönemdeki dengesizliğin ne kadarının uzun dönemde düzeltileceğini göstermektedir. Bu katsayının negatif ve anlamlı olması beklenmektedir. 


\section{Tahmin Sonuçları}

\subsection{Birim Kök Testlerinin Sonuçları}

Tablo 1, ADF ve PP birim kök testlerinin sonuçlarını göstermektedir. Tablodan görüldüğü gibi, her iki teste göre faiz oranları ilk farkında durağanken, borsa endeksi açığı durağandır. Diğer değişkenlerin durağanlık dereceleri ise testlere göre değişmektedir.

Tablo 1. ADF ve PP Birim Kök Testlerinin Sonuçları

\begin{tabular}{lcccc}
\hline Değişken $^{\mathrm{a}}$ & \multicolumn{2}{c}{ ADF Test İstatistiği } & \multicolumn{2}{c}{ PP Test İstatistiği } \\
\cline { 2 - 5 } $\mathrm{i}$ & Sabitli & Sabitli-Trendli & Sabitli & Sabitli-Trendli \\
$\left(\Pi^{\mathrm{e}}-\Pi^{\mathrm{t}}\right)$ & 2,47 & $-3,31$ & $-2,61$ & $-3,31$ \\
$\mathrm{y}^{\text {gap }}$ & $-1,66$ & $-3,83^{\mathrm{b}}$ & $-1,68$ & $-1,96$ \\
exc $^{\text {gap }}$ & $-3,24^{\mathrm{b}}$ & $-2,94$ & $-2,16$ & $-1,64$ \\
sm $^{\text {gap }}$ & $-4,04^{\mathrm{b}}$ & $-4,97^{\mathrm{b}}$ & $-3,03^{\mathrm{b}}$ & $-3,07$ \\
$\Delta \mathrm{i}$ & $-6,29^{\mathrm{b}}$ & $-3,94^{\mathrm{b}}$ & $-5,26^{\mathrm{b}}$ & $-5,98^{\mathrm{b}}$ \\
$\Delta\left(\Pi^{\mathrm{e}}-\Pi^{\mathrm{t}}\right)$ & $-6,21^{\mathrm{b}}$ & $-6,27^{\mathrm{b}}$ & $-6,23^{\mathrm{b}}$ & $-6,27^{\mathrm{b}}$ \\
$\Delta \mathrm{y}^{\text {gap }}$ & $-3,94^{\mathrm{b}}$ & $-4,01^{\mathrm{b}}$ & $-3,93^{\mathrm{b}}$ & $-4,00^{\mathrm{b}}$ \\
$\Delta \operatorname{exc}^{\text {gap }}$ & $-3,10^{\mathrm{b}}$ & $-2,20$ & $-5,39^{\mathrm{b}}$ & $-6,64^{\mathrm{b}}$ \\
$\Delta$ sm $^{\text {gap }}$ & $-4,17^{\mathrm{b}}$ & $-4,06^{\mathrm{b}}$ & $-4,10^{\mathrm{b}}$ & $-4,01^{\mathrm{b}}$ \\
\hline$\% 5 \mathrm{kritik}^{\mathrm{b}}$ değeri & $-2,98^{\mathrm{b}}$ & $-2,93$ & $-4,76^{\mathrm{b}}$ & $-4,64^{\mathrm{b}}$ \\
\hline
\end{tabular}

${ }^{\mathrm{a}} \Delta$ birinci fark işlemcisidir. ${ }^{\mathrm{b}} \% 5$ düzeyinde anlamlılığı göstermektedir.

Tablo 2, Lee ve Strazicich (2003) birim kök testinin sonuçlarını göstermektedir. Bu testin sonuçlarına göre, enflasyon beklentisi ile enflasyon hedefi arasındaki fark ve çıktı açığı durağanken, faiz oranları ve döviz kuru açığı ilk farkında durağandır. Borsa endeksi açığının durağanlık derecesi ise testin modellerine göre farklılık göstermektedir. Görüldüğü üzere, birim kök testlerinin sonuçları ARDL modelinin kullanılmasına işaret etmektedir. 
Tablo 2. Lee ve Strazicich (2003) Birim Kök Testinin Sonuçları

\begin{tabular}{|c|c|c|c|c|}
\hline Değişken $^{a}$ & Model & Test İstatistiği & Kırııma Dönemleri & \%5 kritik Değerib \\
\hline \multirow[t]{2}{*}{ i } & $A$ & $-3,21$ & 2010:4, 2013:4 & $-3,84$ \\
\hline & C & $-5,10$ & $2011: 2,2012: 4$ & $-5,67$ \\
\hline \multirow[t]{2}{*}{$\left(\Pi^{e}-\Pi^{t}\right)$} & $A$ & $-3,94^{c}$ & $2012: 2,2012: 4$ & $-3,84$ \\
\hline & c & $-6,76^{c}$ & 2011:1, 2013:2 & $-5,67$ \\
\hline \multirow[t]{2}{*}{$y^{\text {gap }}$} & A & $-6,68^{c}$ & $2013: 2,2013: 4$ & $-3,84$ \\
\hline & C & $-9,65^{c}$ & $2013: 4,2014: 3$ & $-5,65$ \\
\hline \multirow[t]{2}{*}{ exc gap } & A & $-3,72$ & $2012: 4,2013: 4$ & $-3,84$ \\
\hline & C & $-3,98$ & $2012: 1,2014: 3$ & $-5,65$ \\
\hline \multirow[t]{2}{*}{ sm gap } & A & $-3,73$ & 2013:1, 2013:4 & $-3,84$ \\
\hline & C & $-6,71^{c}$ & $2013: 2,2014: 3$ & $-5,73$ \\
\hline \multirow[t]{2}{*}{$\Delta \mathrm{i}$} & A & $-6,60^{c}$ & & $-3,84$ \\
\hline & C & $-8,91^{c}$ & & $-5,67$ \\
\hline \multirow[t]{2}{*}{$\Delta\left(\Pi^{\mathrm{e}}-\Pi^{\mathrm{t}}\right)$} & A & $-3,87^{c}$ & & $-3,84$ \\
\hline & C & $-6,05^{c}$ & & $-5,67$ \\
\hline \multirow[t]{2}{*}{$\Delta y^{\text {gap }}$} & $A$ & $-8,01^{c}$ & & $-3,84$ \\
\hline & C & $-10,88^{c}$ & & $-5,73$ \\
\hline \multirow[t]{2}{*}{$\Delta \mathrm{exc}^{\mathrm{gap}}$} & A & $-6,77^{c}$ & & $-3,84$ \\
\hline & C & $-14,35^{c}$ & & $-5,65$ \\
\hline \multirow[t]{2}{*}{$\Delta s m^{\text {gap }}$} & $A$ & $-4,23^{c}$ & & $-3,84$ \\
\hline & C & $-5,11$ & & $-5,65$ \\
\hline
\end{tabular}

${ }^{a} \Delta$ birinci fark işlemcisidir. ${ }^{b}$ Kritik değerler, Lee ve Strazicich (2003: 1084)'de yer alan Tablo 2'den alınmıştır. ${ }^{c} \% 5$ düzeyinde anlamlılığı göstermektedir.

\subsection{Eşbütünleşme Testinin Sonuçları}

Daha önce ifade edildiği üzere, ARDL yöntemiyle değişkenler arasındaki uzun dönemli ilişkiyi inceleyebilmek için öncelikle sınır testi yaklaşımı ile seriler arasında uzun dönemli bir ilişkinin olup olmadığı tespit edilmektedir. Sınır testinde ilk olarak SBC'ye göre uygun gecikme uzunluğu belirlenmektedir.

Tablo 3. Sınır Testi İçin Gecikme Uzunluğunun Belirlenmesi

\begin{tabular}{lcccc}
\hline & \multicolumn{2}{c}{ Sabitli } & \multicolumn{2}{c}{ Sabitli ve Trendli } \\
\hline \hline Gecikme Uzunluğu & SBC & LM $^{\mathrm{a}}$ & SBC & LM $^{\mathrm{a}}$ \\
1 & 3,94 & 0,01 & 4,01 & 1,37 \\
2 & 4,28 & 0,01 & 4,02 & 0,46 \\
\hline
\end{tabular}

a $\mathrm{LM}$, otokorelasyonu test etmek için kullanılan Breusch-Godfrey LM test istatistiğidir.

Tablo 3, model için uygun gecikme uzunluğunun 1 olduğunu göstermektedir. Model için uygun gecikme uzunluğunun tespit edilmesinin ardından Tablo 4, bu gecikme uzunluğunda değişkenler arasında eşbütünleşme ilişkisinin olup olmadığını göstermektedir. 
Tablo 4. Sınır Testinin Sonuçları

\begin{tabular}{|c|c|c|c|c|c|}
\hline \multicolumn{6}{|c|}{ Test İstatistikleri } \\
\hline \multirow{2}{*}{\multicolumn{2}{|c|}{$\begin{array}{c}F_{I I I I} \\
5,02^{\mathrm{a}}\end{array}$}} & \multicolumn{2}{|c|}{$F_{I V}$} & \multicolumn{2}{|c|}{$\mathrm{Fv}_{\mathrm{V}}$} \\
\hline & & & & \multicolumn{2}{|c|}{$5,10^{a}$} \\
\hline \multicolumn{6}{|c|}{ \%5 Kritik Değerlerib } \\
\hline $\mathrm{I}(0)$ & I(1) & $\mathrm{I}(0)$ & $\mathrm{I}(1)$ & $I(0)$ & I(1) \\
\hline 2,86 & 4,01 & 3,05 & 3,97 & 3,47 & 4,57 \\
\hline
\end{tabular}

a \%5 düzeyinde anlamlılı̆ı göstermekte olup, eşbütünleşme ilişkisinin varlığına işaret etmektedir. ${ }^{b}$ Kritik değerler, Pesaran vd. (2001: 301-302)'de yer alan Tablo Cl(iii), Tablo Cl(iv) ve Tablo Cl(v)'ten alınmıştır.

Tablo 4'te gösterilen sınır testinin sonuçlarına göre test istatistikleri üst kritik değerlerden yüksektir. Buna göre, modelde yer alan değişkenler arasında eşbütünleşme ilişkisi vardır. Dolayısıyla, değişkenler arasındaki uzun dönemli ve kısa dönemli ilişkilerin tespiti için ARDL modeli kullanılabilir. ARDL modelinden elde edilen uzun dönem katsayıları Tablo 5'te gösterilmektedir. ${ }^{5}$

Tablo 5. Uzun Dönem Katsayıları

\begin{tabular}{lcc}
\hline Değişken & Katsayı & Prob. Değeri \\
\hline \hline Sabit & $4,64^{\mathrm{b}}$ & 0,03 \\
$\left(\Pi^{\mathrm{e}}-\Pi^{\mathrm{t}}\right)$ & $5,31^{\mathrm{a}}$ & 0,00 \\
$\mathrm{y}^{\text {gap }}$ & $-122,95^{\mathrm{b}}$ & 0,02 \\
exc $^{\text {gap }}$ & $53,14^{\mathrm{c}}$ & 0,06 \\
sm $^{\text {gap }}$ & 4,01 & 0,69 \\
\hline
\end{tabular}

a \%1 düzeyinde anlamlılığı göstermektedir. ${ }^{b} \% 5$ düzeyinde anlamlılı̆̆ı göstermektedir. ${ }^{c} \% 10$ düzeyinde anlamlılığı göstermektedir.

Tablo 5'te görüldüğü gibi, 12 ay sonrasının yıllık enflasyon beklentisi ile 12 ay sonrasının yıllık enflasyon hedefi arasındaki farkın katsayısı pozitif ve anlamlıdır. Buna göre, enflasyon beklentisi ile enflasyon hedefi arasındaki fark yükseldikçe (düştükçe) TCMB faiz oranlarını artırmaktadır (azaltmaktadır). TCMB'nin faiz oranlarını yükseltmesindeki amaç toplam talebi sınırlayarak enflasyonun hedefe yakın olmasını sağlamaktır. Uygulama sonuçlarına göre çıktı açığının katsayısı negatif ve anlamlıdır. Teoride bu katsayının pozitif olması beklenebilir. Katsayının işaretinin beklenenin aksine pozitif olmasını nedeni TCMB’nin enflasyon konusunda olduğu gibi çıktı konusunda da ileri bakışı bir tutum içinde olması olabilir; ancak bu konu hakkında daha sağlıklı yorumlar için çıktı açığının gecikmeli değeri yerine çıktı açığı beklentisini kullanan çalışmalara ihtiyaç vardır. Uygulama sonuçlarının gösterdiği bir diğer bulgu, döviz kuru açığının katsayısının pozitif ve anlamlı olmasıdır. Buna göre TCMB, TL'nin döviz kuru sepeti karşısındaki değeri uzun vadeli trendinin ne kadar altında kalırsa faiz oranlarını o kadar yükseltmektedir. TCMB'nin bunu yapmasındaki amacı Türkiye ekonomisine yönelik yabancı sermaye girişlerini etkileyebilmektir. Buna göre, döviz kurlarındaki hızlı yükselmeler karşısında TL'nin döviz kuru sepeti karşısındaki değerini korumak için TCMB kısa vadeli faiz oranlarını artırmakta ve kısa vadeli faiz oranlarında

\footnotetext{
${ }^{5}$ Alandan tasarruf etmek için uzun ve kısa dönem ARDL modelleri ve bu modellerden elde edilen katsayıların istikrarını gösteren CUSUM ve CUSUM-Q testlerinin sonuçları çalışmada sunulmamıştır. Uzun dönem ARDL modeline göre, faiz oranının 1 dönem gecikmeli değerinin katsayısı anlamsız olduğundan TCMB faiz düzleştirmesi yapmamaktadır. Kısa dönem ARDL modelinden elde edilen sonuçlar, hata düzeltme teriminin 1 dönem gecikmeli değerinin katsayısının beklendiği gibi negatif ve anlamlı olduğuna işaret ettiğinden, modeldeki kısa dönemli dengesizlikler uzun dönemde giderilmektedir. CUSUM ve CUSUM-Q testleri ise, uzun ve kısa dönem katsayıların istikrarlı olduğunu göstermektedir. Söz konusu modeller ve sonuçlar, yazardan istenilebilir.
} 
yükselmeler ise daha uzun vadeli TL cinsi yatırım araçlarının (mevduat, devlet tahvili vs.) getirilerini yükseltmektedir. TCMB, TL cinsi yatırım araçlarının getirilerinin yükselmesine sağlayarak Türkiye ekonomisine daha fazla yabancı sermayenin girmesini ve TL'deki değer kaybının hafiflemesini arzu etmektedir. Modeldeki bir diğer değişken borsa endeksi açı̆̆ının katsayısı ise anlamsızdır. Teoride borsa endeksi açığının katsayısının pozitif olması beklenebilir. Bunun nedeni, borsa endeksinde görülecek çok hızlı yükselmeler karşısında TCMB'nin hem borsaya yatırım yapmanın maliyetini (kredi faizlerini) hem de borsaya alternatif yatırım araçlarının (mevduat, devlet tahvili) getirilerini yükseltmek için faiz oranlarını yükseltebilmesidir. Ancak tabloda görüldüğü gibi, TCMB faiz oranlarını borsa endeksi açığındaki değişimler karşısında değiştirmemektedir.

Bu sonuçlara göre, TCMB kısa vadeli faiz oranlarını ayarlarken, finansal değişken olarak döviz kuruyla ilgilenmektedir. Diğer bir ifadeyle, döviz kuru, enflasyon bekleyişlerini etkilemesinin ötesinde TCMB'nin faiz ayarlamaları üzerinde anlamlı etkilere sahiptir. Buna göre TCMB, döviz kurunda yüksek oynaklık istememekte ve faiz oranlarını oynaklığı azaltacak şekilde kullanmaktadır.

\section{Sonuç}

2008 küresel krizinden önce merkez bankacılar ve akademisyenler arasındaki yaygın görüşe göre, merkez bankaları finansal değişkenlerle yalnızca bu değişkenler çıktıyı ve enflasyonu etkilediği sürece ilgilenmelidir. Bu görüşe göre, fiyat istikrarını sağlayabilen bir merkez bankası finansal istikrara da katkıda bulunabilecektir. 2008 krizi ise, finansal sektörde yaşanan gelişmelerin ekonomik faaliyetler üzerinde çok ciddi etkilerinin olduğunu göstermiştir. Bu çerçevede kriz, fiyat istikrarına odaklanan merkez bankalarının finansal sistemdeki riskleri ve varlık fiyatlarındaki gelişmeleri inmal etmemesi gerektiğini ortaya koymuştur. Bu nedenle, krizden sonra çeşitli merkez bankalarının tepki fonksiyonlarını tahmin eden çalışmalarda tepki fonksiyonlarına finansal değişkenler eklenmiştir.

Bu çalışmada TCMB'nin tepki fonksiyonu varlık fiyatlarıyla genişletilmiş ve küresel krizi izleyen dönemde TCMB'nin varlık fiyatlarına tepki verip vermediği incelenmiştir. Çalışmada ilk olarak, ADF, PP ve Lee ve Strazicich (2003) birim kök testleriyle değişkenlerin durağanlık dereceleri tespit edilmiş ve devamında ARDL yaklaşımıyla değişkenler arasında eşbütünleşme ilişkisinin var olduğu belirlenmiştir. Devamında ise, ARDL yaklaşımıyla değişkenlere ait uzun dönem katsayılar elde edilmiştir. Ampirik analizin sonuçlarına göre, gecelik faiz oranları enflasyon beklentisi ile enflasyon hedefi arasındaki farkla ve döviz kuru açığıyla pozitif ve çıktı açığıyla negatif ilişkiliyken, borsa endeksi açığının katsayısı anlamsızdır. Buna göre, TCMB enflasyon beklentisi ile enflasyon hedefi arasındaki fark yükseldikçe, ekonomideki enflasyonist baskıları hafifletmek için faiz oranlarını yükseltmektedir. Çıktı açığının gecikmeli değerinin katsayısının beklenenin aksine negatif olması, TCMB'nin esas olarak çıktı açığı beklentisindeki değişimleri dikkate aldığına işaret edebilir; ancak daha sağlıklı yorumlar için TCMB'nin tepki fonksiyonuna çıktı açığı beklentisini ilave eden çalışmalara ihtiyaç vardır. Çalışmadan elde edilen diğer önemli bulguya göre ise, döviz kuru enflasyon beklentilerini etkilemenin ötesinde TCMB'nin faiz ayarlamaları üzerinde doğrudan etkiye sahiptir. Buna göre TCMB, TL'nin değeri uzun vadeli trendinin ne kadar üzerine çıkarsa faiz oranlarını o kadar düşürmekte, ne kadar altında kalırsa faiz oranlarını o kadar yükseltmektedir. Çalışmanın bulguları, küresel krizi izleyen dönemde TCMB'nin sadece enflasyon ile değil, aynı zamanda döviz kurunun seviyesiyle de doğrudan ilgilendiğini göstermektedir. 


\section{Kaynaklar}

ABDioĞLU, Z. ve H. TERZi (2009), "Enflasyon ve Bütçe Açıkları İlişkisi: Tanzi ve Patinkin Etkisi”, Atatürk Üniversitesi iktisadi ve Idari Bilimler Fakültesi Dergisi, 23(2), 195-211.

ADANUR-AKLAN, N. ve M. NARGELEÇEKENLER (2008), "Taylor Rule in Practice: Evidence from Turkey", International Advances in Economic Research, 14(2), 156-166.

AGENOR, P. R. Ve L. A. P. SILVA (2012), "Macroeconomic Stability, Financial Stability, and Monetary Policy Rules", International Finance, 15(2), 205-224.

BERNANKE, B. ve M. GERTLER (2000), "Monetary Policy and Asset Price Volatility", NBER Working Paper Series, 7559.

BERNANKE, B. Ve M. GERTLER (2001), “Should Central Banks Respond to Movements in Asset Prices?”, The American Economic Review, 91(2), 253-257.

BERUMENT, H. ve K. MALATYALI (2000), "The Implicit Reaction Function of the Central Bank of the Republic of Turkey", Applied Economics Letters, 7(7), 425-430.

BERUMENT, H. ve H. TAŞÇI (2004), “Monetary Policy Rules in Practice: Evidence from Turkey”, International Journal of Finance and Economics, 9, 33-38.

BOFINGER, P., REISCHLE, J. ve A. SCHACHTER (2001), Monetary Policy: Goals, Institutions, Strategies, and Instruments, New York: Oxford University Press.

BULUT, Ü. (2016), “How Far Ahead Does the Central Bank of the Republic of Turkey Look?”, Journal of Central Banking Theory and Practice, 5(1), 99-111.

CASTRO, V. (2011), "Can Central Banks' Monetary Policy Be Described by a Lineer (Augmented) Taylor Rule or by a Nonlinear Rule?", Journal of Financial Stability, 7(4), 228-246.

CECCHETTI, S. G. (2003), "What the FMOC Says and Does When the Stock Market Booms", Ed. Anthony Richards ve Tim Robinson, Asset Prices and Monetary Policy, Australia: Reserve Bank of Australia, 77-96.

CLARIDA R. Ve M. GERTLER (1997), “How the Bundesbank Conducts Monetary Policy”, Ed. Christina D. Romer ve David H. Romer, Reducing Inflation: Motivation and Strategy, Chicago: University of Chicago Press, 363-412.

CLARIDA, R., GALI, J. ve M. GERTLER (1998), “Monetary Policy Rules in Practice: Some International Evidence”, European Economic Review, 42(6), 1033-1067.

CLARIDA, R., GALI, J. ve M. GERTLER (1999), "The Science of Monetary Policy: A New Keynesian Perspective", Journal of Economic Literature, 37(4), 1661-1707.

CLARIDA R., GALI, J. ve M. GERTLER (2000), “Monetary Policy Rules and Macroeconomic Stability: Evidence and Some Theory", The Quarterly Journal of Economics, 115(1), 147-180.

DARICI, B. (2010), "Kısa Vadeli Para Politikası Aracı Olarak Faiz Düzleştirme Kuralı: Teorik ve Metodolojik Yaklaşım”, BDDK Bankacılık ve Finansal Piyasalar Dergisi, 4(2), 39-66.

DICKEY, D. A. ve W. A. FULLER (1979), "Distribution of the Estimators for Autoregressive Time Series with a Unit Root", Journal of the American Statistical Association, 74(366), 427-431.

DICKEY, D. A. ve W. A. FULLER (1981), "Likelihood Ratio Statistiscs for Autoregressive Time Series with a Unit Root", Econometrica, 49(4), 105-1072.

ENGLE, R. F. ve C. W. J. GRANGER (1987), “Co-integration and Error Correction: Represantation, Estimation, and Testing", Econometrica, 55(2), 251-276.

EICHENGREEN, B., EL-ERIAN, M., FRAGA, A., ITO, T., PISANI-FERRY, J., PRASAD, E., RAJAN, R., RAMOS, M., REINHART, C., REY, H., RODRIK, D., ROGOFF, K., SHIN H.S., VALESCO, A., MAURO, B., and Y. YU (2011), "Rethinking Central Banking", http://www.brookings.edu/ /media/research/files/reports/2011/9/ciepr-central-banking/rethinkingcentral-banking.pdf, (Erişim: 01.01.2014).

ERDEM, E. ve S. KAYHAN (2010), The Taylor Rule in Estimating the Performance of Inflation Targeting Programs: The Case of Turkey, International Trade and Finance Association 20th International Conference, Las Vegas.

FAUST, J., ROGERS, J. H. ve J. H. WRIGHT (2001), “An Empirical Comparison of Bundesbank and ECB Monetary Policy Rules", Board of Governors of the Federal Reserve System International Finance Discussion Papers, 705.

FRIEDMAN, B. (2012), "Rules versus Discretion at the Federal Reserve: On to the Second Century", Journal of Macroeconomics, 34(3), 608-615.

FURLANETTO, F. (2011), "Does Monetary Policy React to Asset Prices? Some International Evidence", International Journal of Central Banking, 7(3), 91-111. 
GÖZGÖR, G. (2012), “Inflation Targeting and Monetary Policy Rules: Further Evidence from the Case of Turkey”, Journal of Applied Finance \& Banking, 2(5), 127-136.

GRANGER, C. W. J. ve P. NEWBOLD (1974), Spurious Regression in Econometrics. Journal of Econometrics, 2(2), 111120.

HODRICK, R. J. ve E. C. PRESCOTT (1997), “Postwar U.S. Business Cycles: An Empirical Investigation”, Journal of Money, Credit and Banking, 29(1), 1-16.

IKLAGA, F.O. (2008), "Estimating a Monetary Policy Reaction Function for the Central Bank of Nigeria (1999-2007)", Unpublished Paper, Columbia University.

ISSING, O. (2011), “Lessons for Monetary Policy: What Should the Consensus Be?”, IMF Working Paper, 97.

JOHANSEN, S. (1988), "Statistical Analysis of Cointegration Vectors", Journal of Economic Dynamics and Control, 12(23), 231-254.

JOHANSEN, S. ve K. JUSELIUS (1990), “Maximum Likelihood Estimation and Inference on Cointegration - with Applications to the Demand for Money", Oxford Bullettin of Economics and Statistics, 52(2), 169-210.

JUDD, J. P. ve G. D. RUDEBUSCH (1998), "Taylor's Rule and the FED: 1970-1997”, Federal Reserve Bank of San Francisco Economic Review, 3, 3-16.

KARA A. H. (2012), “Küresel Kriz Sonrası Para Politikası”, iktisat işletme ve Finans, 27(315), 9-36.

KAYTANCI, B. G. (2008), Estimating the Monetary Reaction Function for Turkey, 8th Global Conference on Business \& Economics, İtalya.

KENNEDY, P. (2006), Ekonometri Kılavuzu, Çev. Muzaffer Sarımeşeli ve Şenay Açıkgöz, Ankara: Gazi Kitabevi.

KESRIYELI, M. ve C. YALÇIN (1998), "Taylor Kuralı ve Türkiye Uygulaması Üzerine Bir Not”, TCMB Araştırma Genel Müdürlüğü Tartışma Tebliği, 9802.

KUMAR, S. (2013), “Financial Crisis, Taylor Rule and the FED”, Applied Economics Letters, 20(17), 1557-1561.

LANGE, R. H. (2013), "Monetary Policy Reactions and the Exchange Rate: A Regime-Switching Structural VAR for Canada", International Review of Applied Economics, 27(5), 612-632.

LEBE, F. ve T. BAYAT (2011), “Taylor Kuralı: Türkiye İçin Bir Vektör Otoregresif Model Analizi”, Ege Akademik Bakış, 11, 95-112.

LEE, J. ve M. C. STRAZICICH (2003), "Minimum Lagrange Multiplier Unit Root Test with Two Structural Breaks", The Review of Economics and Statistics, 85(4), 1082-1089.

LEE, D. J. ve J. C. SON (2013), “Nonlinearity and Structural Breaks in Monetary Policy Rules with Stock Prices”, Economic Modelling, 31, 1-11.

MAH, J. S. (2000), "An Empirical Examination of the Disaggregated Import Demand of Korea-The case of Information Technology Products", Journal of Asian Economics, 11(2), 237-244.

MILAS, C. Ve R. NARAIDOO (2012), "Financial Conditions and Nonlinearities in the European Central Bank (ECB) Reaction Function: In-sample and out-of-sample Assessment", Computational Statistics \& Data Analysis, 56(1), 173189.

NARAYAN, S. ve P. K. NARAYAN (2004), “Determinants for Demand for Fiji's Exports: An Empirical Investigation”, The Developing Economics, 42(1), 95-112.

ÖZATAY, F. (2012), "Para Politikasında Yeni Arayışlar", iktisat Iş̧letme ve Finans, 27(315), 51-75.

ÖZTÜRK, i. ve A. ACARAVCI (2011), "Electricity Consumption and Real GDP Causality Nexus: Evidence from ARDL Bounds Testing Approach for 11 MENA Countries", Applied Energy, 88(8), 2285-2292.

PERRON, P. (1989), "The Great Crash, the Oil Price Shock, and the Unit Root Hypothesis", Econometrica, 57(6), 13611401.

PESARAN, M. H. ve Y. SHIN (1999), "An Autoregressive Distributed Lag Modelling Approach to Cointegration Analysis", Ed. Steinar Strom, Econometrics and Econometric Theory in the 20th Century: The Ragnar Frisch Centennial Symposium, Cambridge: Cambridge University Press, 371-413.

PESARAN, M. H., SHIN, Y. ve R. J. SMITH (2001), "Bounds Testing Approach to the Analysis of Level Relationships", Journal of Applied Econometrics, 16(3), 289-326.

PHILLIPS, P. C. B. ve P. PERRON (1988), “Testing for a Unit Root in Time Series Regression”, Biometrika, 75(2), 335-346.

PEHLivANOĞLU, F. (2014), “Optimal Para politikası Çerçevesinde Taylor Tipi Faiz Oranı Reaksiyon Fonksiyonunun Tahmini: Türkiye Örneği”, Bilgi Ekonomisi ve Yönetimi Dergisi, 9(1), 115-126. 
Eskişehir Osmangazi Üniversitesi IiBF Dergisi

RAMAYANDI, A. (2003), "Tracing the Monetary Policy Reaction Functions for the Case of a Small Developing Economy", Padjadjaran University Department of Economics Working Paper in Economics and Development Studies, 200301.

SEVÜKTEKiN, M. ve M. NARGELEÇEKENLER (2010), Ekonometrik Zaman Serileri Analizi, Üçüncü Baskı, Ankara: Nobel Yayın Dağıtım.

SHIBAMOTO, M. (2008), "The Estimation of Monetary Policy Reaction Function in a Data-Rich Environment: The Case of Japan", Japan and the World Economy, 20(4), 497-520.

SUTHERLAND, D. (2010), “Monetary Policy Reaction Functions in the OECD”, OECD Economics Department Working Papers, 761.

STRAZICICH, M. C., LEE, J. ve E. DAY (2004), “Are Incomes Converging Among OECD Countries? Time Series Evidence with Two Structural Breaks", Journal of Macroeconomics, 26(1), 131-145.

SVENSSON, L. E. O. (2010a), Inflation Targeting after the Financial Crisis, Challanges to Central Banking in the Context of Financial Crisis Conference, Mumbai.

SVENSSON, L. E. O. (2010b), Inflation Targeting and Financial Stability, Conference of CEPR/ESI, İzmir.

TAYLOR, J. (1993), Discretion versus Policy Rules in Practice, Carnegie-Rochester Conference Series on Public Policy, North Holland.

YAPRAKLI, S. (2007), "Türkiye'de Enflasyon ve Döviz Kurunun Para Politikası Kuralı Üzerindeki Etkisi”, iktisat Işletme ve Finans, 22(258), 122-135.

YAZGAN, M. E. ve H. YILMAZKUDAY (2007), “Monetary Policy Rules in Practice: Evidence from Turkey and Israel”, Applied Financial Economics, 17(1), 1-8.

http://tcmb.gov.tr/, (Erişim: 15.04.2016)

http://www.trlibor.org/, (Erişim: 15.04.2016) 